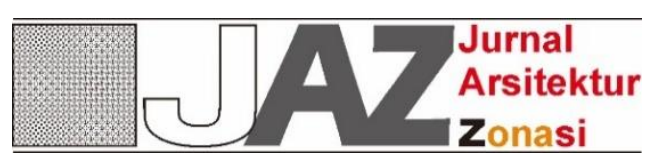

http://ejournal.upi.edu/index.php/jaz - e-mail: jurnal.zonasi@gmail.com dan jurnal_zonasi@upi.edu doi.org/10.17509/jaz.v3i2.24898

\title{
KAJIAN KONSEP ARSITEKTUR HIJAU PADA BANGUNAN MUSEUM GEOLOGI STUDI KASUS : MUSEUM GEOLOGI BANDUNG
}

\author{
Article History: \\ First draft received: \\ 26 Mei 2020 \\ Revised: \\ 15 Juni 2020 \\ Accepted: \\ 22 Juni 2020 \\ Final proof received: \\ Print: \\ 30 Juni 2020 \\ Online \\ 4 Juli 2020
}

Jurnal Arsitektur ZONASI is indexed and listed in several databases:

SINTA 4 (Arjuna)

GARUDA (Garda Rujukan Digital)

Google Scholar

Dimensions

oneSearch

BASE

Member:
Crossref
RJI
APTARI
FJA (Forum Jurna Arsitektur)
IAI
AJPKM

AJPKM

\author{
Muhammad Ghiyas Ghurotul Muhajjalin ${ }^{1}$ \\ Anggana Fitri Satwikasari ${ }^{2}$ \\ ${ }^{1,2}$ Universitas Muhammadiyah Jakarta, Jakarta, Indonesia \\ Jl. Cempaka Putih Tengah 27, RT.11/RW.5, Cemp. Putih Tim., Kec. Cemp. Putih, Kota \\ Jakarta Pusat, Daerah Khusus Ibukota Jakarta 10510 \\ Email: 2016460030@ftumj.ac.id \\ Anggana.fitri@ftumj.ac.id
}

Abstract: Concern for nature must indeed be considered, because to prevent undesirable effects such as global warming or damage to the surrounding environment. The cause of this impact is a result of nature and even human actions themselves, such as due to volcanoes erupting, waste disposal, vehicle pollution, and others. But there are also causes of other things, namely the establishment of a building without looking at the surrounding environment, which only emphasizes the function and aesthetics, so it becomes a very important problem. Green architecture is a concept where buildings to be erected must have criteria to support the natural surroundings, so this concept is very used to minimize or prevent natural damage caused by buildings. An example of the building that will be applied in this research is the Geology Museum, considering that Indonesia has a complex geographical location and natural wealth from the bowels and extraterrestrial. The method used in this research is a qualitative descriptive method, which is the depiction or explaining the facts in the field by analyzing and discussing them broadly so that they can find results and conclusions.

Keywords: Green Architecture, Museum, Qualitative Descriptive.

Abstrak: Kepedulian terhadap alam memang harus diperhatikan, karena untuk mencegah dampak-dampak yang tidak diinginkan seperti pemanasan bumi atau kerusakan lingkungan sekitar. Penyebab dari dampak ini merupakan akibat dari alam bahkan perbuatan manusia itu sendiri, seperti akibat gunung berapi meletus, pembuangan limbah, polusi kendaraan, dan lain-lain. Namun ada juga penyebab dari hal lain yaitu berdirinya suatu bangunan tanpa melihat lingkungan sekitarnya, yang hanya mementingkan fungsi maupun estetikanya, sehingga menjadi suatu permasalahan yang sangat penting. Arsitektur hijau merupakan sebuah konsep dimana bangunan yang akan didirikan harus memiliki kriteria untuk mendukung alam sekitar, sehingga konsep ini sangat digunakan untuk meminimalisir atau mencegah terjadinya kerusakan alam yang disebabkan oleh bangunan. Sebagai contoh bangunan yang akan diterapkan pada penelitian ini adalah Museum Geologi, mengingat Indonesia memiliki letak geografis yang kompleks dan kekayaan alam dari perut dan luar bumi. Metode yang digunakan dalam penelitian ini adalah metode deskriptif kualitatif, yaitu penggambaran atau menjelaskan fakta-fakta yang ada di lapangan dengan cara menganalisis serta membahasnya secara luas sehingga dapat menemukan hasil dan kesimpulan.

Kata Kunci: Arsitektur Hijau, Museum, Deskriptif Kualitatif.

\section{Pendahuluan}

Kerusakan alam menjadi salah satu bencana besar bagi dunia, tidak terkecuali seperti pemanasan global, pembuangan limbah, polusi dan lain-lain. Keseimbangan antara lingkungan dan sekitarnya juga merupakan hal yang sangat penting, mengingat generasi penerus kita semua akan menikmati keindahan serta 
kekayaan alamnya. Namun, dari kita semua semakin sedikit yang peduli tentang hal tersebut. Banyak penyebab yang membuat alam kita rusak, seperti didirikannya bangunan tanpa melihat lingkungan sekitarnya, yang hanya mementingkan fungsi serta estetika tanpa melihat pohon-pohon yang tumbuh di area tersebut.

Indonesia juga merupakan negara yang sangat mudah terkena dampak bencana alam mapun buatan, dan banyak sekali yang tidak memikirkan ataupun peduli mengapa ini terjadi. Seperti baru-baru ini yang sedang memanasnya yaitu kabut asap di Riau dan sekitarnya, hal ini dikarenakan pembakaran dan perusakan hutan oleh manusia yang serakah dan hanya ingin mengambil keuntungan tanpa memikirkan kerugian yang akan didapatkan. Namun, ada kalanya kabut asap juga disebabkan secara alami, seperti dari gunung meletus, maupun cuaca yang panas sehingga terjadinya gesekan antara pohon-pohon yang kering dan mengakibatkan kebakaran.

Tidak berbeda dengan bangunan, yang mana bangunan juga menyumbang kerusakan pada lingkungan disekitarnya. Hal ini disebabkan banyaknya pemakaian kaca yang berlebih serta tidak memikirkan iklim. Bukan hanya itu, terkadang orang-orang lebih mementingkan berdirinya sebuah bangunan tanpa melihat lingkungan sekitarnya. Hal ini tentu menjadi permasalahan yang besar bagi kelangsungan hidup kita untuk kedepannya.

\subsection{Arsitektur Hijau}

Berdasarkan permasalahan, tentu harus ada solusi untuk menghentikannya, setidaknya mengurangi kontribusi bangunan dalam perusakan lingkungan. Salah satu caranya adalah mendirikan sebuah bangunan dengan penerapan konsep arsitektur hijau. Arsitektur hijau merupakan arsitektur yang mencakup mengenai alam serta kepedulian mengenai pemeliharaan atau perlindungan terhadap lingkungan sekitar, dengan memperhatikan terhadap energy efficient (efisiensi energi), (sustainable concept) konsep berkelanjutan, serta holistic application (penerapan holistik) (Priatman, 2002). Arsitektur hijau juga merupakan sebuah pengenalan untuk merencanakan arsitektur dengan meminimalisir dampak buruk terhadap kesehatan manusia maupun lingkungan sekitarnya, sehingga memiliki tujuan utama seperti menciptakan eco desain, kepedulian terhadap lingkungan, menciptakan arsitektur yang alami serta arsitektur yang berkelanjutan (Rusadi, Purwatiasning, \& Satwikasari, 2019). Sedangkan menurut (Syarif \& Amri, 2017) menjelaskan bahwa arsitektur hijau adalah salah satu konsep yang dipakai oleh arsitektur dengan tujuan untuk terciptanya kondisi yang ekologis serta ramah lingkungan sehingga mendapatkan keseimbangan yang baik antara manusia, bangunan dan lingkungan.

Dapat disimpulkan bahwa aristektur hijau merupakan salah satu konsep yang lebih memanfaatkan sumber daya alam dibanding sumber daya buatan, hal ini mengingat kesadaran kita akan dampak-dampak yang ditimbulkan jika terus-menerus menggunakan sumber energi buatan terhadap manusia maupun bangunan itu sendiri. Karena arsitektur hijau juga merupakan sebuah konsep yang mempelajari berkelanjutan, maksudnya adalah arsitektur hijau mengurangi pemakaian sumber energi yang tidak dapat diperbaharui dengan tujuan agar tidak cepat habis pakai dan menjamin untuk generasi yang akan datang agar bisa merasakan juga (Afifah, Anisa, \& Hakim, 2018). Untuk contoh penerapannya menurut (Utsman, Suroto, \& Winarto, 2019) adalah bisa meminimalkan pemakaian sumber daya terutama sumber daya yang tidak dapat diperbaharui, penggunaan site atau lahan dengan tidak mengganggu lingkungan sekitarnya, serta dapat mengolah barang bekas menjadi barang yang dapat digunakan untuk kepentingan arsitektur, sehingga menjadi salah satu alternatif untuk bisa menghemat biaya. Menurut (Rachmayanti \& Roesli, 2014) arsitektur hijau juga memiliki manfaat-manfaat untuk kelangsungan hidup bagi manusia, bangunan maupun lingkungan sekitarnya, seperti penghematan energi, bangunan memiliki daya tahan yang lebih lama, meminimalkan perawatan terhadap bangunan, memberikan kesehatan dan kenyamanan bagi pemilik, serta dapat mengurangi pemanasan bumi.

Dampak rumah kaca juga mengakibatkan perubahan iklim yang ekstrim, terganggunya ekologis, bahkan terjadinya suhu yang meningkat. Maka dari itu arsitektur hijau dapat mengembangkan efisiensi penggunaan energi dan air, serta penggunaan material-material yang mereduksi pengaruh bangunan dengan manusia terhadap kesehatan (Henriyanto, 2016). Sehingga arsitektur hijau menjadi langkah untuk merancang suatu bangunan, baik itu kawasan maupun perkotaan yang dapat mengurangi gas rumah kaca (Karyono, 2010).

Menurut (Putri, Singgih, \& Gunawan, 2019) ada empat prinsip yang harus diterapkan pada bangunan dengan konsep arsitektur hijau, antara lain material (ramah lingkungan, bisa diperbaharui, dapat diolah dari barang bekas menjadi barang siap pakai, hemat biaya dan energi), kesehatan (kemananan dan kenyamanan bagi pengguna), air (daur ulang air hujan dan limbah, hemat pemakaian air) serta energi alami (memanfaatkan energi alami seperti cahaya matahari, angin). Sedangkan menurut Brenda dan Robert Vale dalam bukunya 'Green Architecture : Design For A Sustainable Future', terdapat enam prinsip antara lain conserving energy / hemat energi, working with climate / penyesuaian terhadap iklim, respect for site / menanggapi keadaan tapak 
pada bangunan, respect for user / memperhatikan pengguna atau pemilik bangunan, limitting new resources / meminimalkan sumber daya, dan holistic / menyeluruh.

\subsection{Bangunan}

Bangunan merupakan suatu dinding dan lain-lain yang berdimensi besar sebagai tempat untuk beraktifitas, seperti bangunan kantor, pendidikan, pertemuan, perdagangan dan lain-lain (Kalukar, Tumaliang, \& Tuege, 2015). Bangunan juga bisa diartikan sebagai konstruksi teknik terhadap bumi atau disimpan secara permanen disekitar tanah maupun perairan sehingga bisa difungsikan untuk tempat tinggal, tempat usaha maupun yang lain (Kakunsi, 2013). Sebagai contoh bangunan yang akan diteliti merupakan bangunan museum geologi, mengingat Indonesia sendiri memiliki letak geografis yang kompleks serta kekayaan alam baik dari luar maupun perut bumi.

\subsection{Museum}

Menurut (Noor \& Karwina, 2012) pembangunan museum telah terjadi perubahan, yang mana definisi museum sebagai tempat untuk menyimpan dan memamerkan koleksi, saat ini museum di dunia berusaha untuk memberikan kesan suasana serta pengalaman yang baru dan berbeda, baik dari tujuan, misi, penunjang, dan sebagainya sehingga membuat pengunjung akan merasakan keamanan dan kenyamanan baik di dalam museum maupun sekitarnya.

Museum sendiri merupakan sebuah bangunan bersifat publik yang bertujuan untuk memamerkan benda-benda nyata dan bersejarah demi kepentingan pendidikan maupun kesenangan. Sehingga harapannya, bangunan museum khususnya museum geologi bisa menerapkan beberapa prinsip arsitektur hijau untuk kepentingan pengguna maupun lingkungan sekitar. Bangunan publik juga merupakan fasilitasnya yang identik sebagai pusat pelayanan untuk masyarakat, seperti kebutuhan pemerintahan, perekonomian, keamanan serta kebutuhan lain. Sehingga Pemerintah setempat bisa mengembangkan aktifitas tersebut diberbagai sektor demi kepentingan cita-cita masyarakat yang diharapkan (Dewanto, 2010).

Menurut International Council of Museum (ICOM), museum adalah suatu lembaga yang memilki sifat tetap, tidak mencari untung, melayani secara umum serta pengembangannya bersifat terbuka, mendapat, menjaga, menginfokan bahkan memamerkan peninggalan-peninggalan tentang jati diri manusia terhadap lingkungan sekitar demi kepentingan pendidikan serta wisata. Museum juga bukan hanya tempat penyimpanan benda-benda tua maupun antik semata, bahkan museum juga dijadikan sebagai tempat untuk penelitian, pendidikan, bahkan konservasi, dimana museum harus terbuka dan bermanfaat untuk masyarakat umum (Wulandari, 2014)

Dapat disimpulkan bahwa museum merupakan sebuah tempat yang bersifat terbuka atau umum dengan tujuan untuk melayani kebutuhan masyarakat, yang aktifitas didalamnya seperti merawat, mengoleksi, mengkonservasi, serta memamerkan benda nyata untuk kepentingan pendidikan masyarakat, memberikan informasi bahkan kesenangan. Sehingga museum hanya dapat dipahami serta diartikan karena fungsi dan kegiatannya itu sendiri (Susanto, 2014), maksudnya adalah bangunan itu bisa disebut dengan museum asalkan syaratnya sesuai dengan fungsi dan kegiatannya, seperti menyimpan koleksi, menjaganya, merawat, dan sebagai tempat untuk penelitian.

\subsection{Museum Geologi}

Museum Geologi merupakan sebuah museum yang melayani informasi tentang kebumian, baik itu hal struktur, komposisi, karakter, bahkan sejarahnya. Museum Geologi juga merupakan bangunan yang bertipe tempat pendidikan maupun tempat wisata. Dimana hal ini merupakan sebagai sarana untuk menambah wawasan, pengalaman serta kesenangan bagi pengunjung yang datang

\section{Metode Penelitian}

Metode yang dipakai pada penelitian ini merupakan metode deskriptif kualitatif, yaitu penggambaran atau menjelaskan kejadian sebenarnya dengan cara menganalisis serta membahasnya secara luas sehingga dapat menemukan hasil dan kesimpulan. Penelitian ini akan menerapkan konsep arsitektur hijau terhadap bangunan museum geologi, yang nantinya akan membahas tentang permasalahan serta kebutuhan antara bangunan dengan lingkungan sekitarnya.

Untuk metode pencarian literatur, penelitian ini menggunakan data primer serta sekunder. Data primer adalah kegiatan untuk mengamati proses atau objek keadaan sekitar, dengan maksud merasakan serta melihat langsung sehingga bisa memahami apa yang terjadi, yang kemudian dituangkan dalam sebuah catatan. Observasi juga dilakukan untuk mengamati keadaan fisik dan non fisik, seperti bentuk dan letak bangunannya, 
keadaan sekitar bangunan, iklim nya, dan lain-lain. Observasi bisa dimanfaatkan dengan cara menulis disebuah catatan, atau bisa juga dengan dokumentasi yang berupa digital seperti foto, video, atau rekaman sehingga hal ini bertujuan untuk menguatkan penelitian ketika mengambil data. Sedangkan untuk data sekunder adalah dengan diperbanyaknya mencari literatur seperti jurnal yang membahas tentang arsitektur hijau.

Metode analisis ini dilakukan dengan penjabaran kondisi eksisting yang dikaitkan berdasarkan prinsip arsitektur hijau menurut Brenda dan Robert Vale dalam bukunya 'Green Architecture : Design For A Sustainable Future", dengan studi kasus Museum Geologi Bandung, Jawa Barat. Prinsip-prinsip tersebut adalah conserving energy / hemat energi, working with climate / penyesuaian terhadap iklim, respect for site / menanggapi keadaan tapak pada bangunan, respectfor user / memperhatikan pengguna atau pemilik bangunan, limitting new resources / meminimalkan sumber daya, dan holistic / menyeluruh.

\section{Hasil dan Pembahasan}

\subsection{Gambaran Umum}

Museum ini berlokasi di Jl. Diponegoro No.57, Cihaur Geulis, Kecamatan Cibeunying Kaler, Kota Bandung, Jawa Barat. Museum ini memiliki luas bangunan $\pm 3.617,08 \mathrm{~m}^{2}$ dengan luas kawasannya $\pm 8.342,52$ $\mathrm{m}^{2}$, yang berarti sekitar $\pm 4.725,44$ atau $56 \%$ merupakan area hijau baik itu desain aktif maupun desain pasif.

\subsubsection{Data Fisik}

a. Bangunan

Museum ini terdiri dari 2 lantai serta menerapkan gaya arsitektur Art Deco dengan memiliki kesan horisontal yang kuat, sehingga masih bisa dilihat museum ini seperti bangunan pada masa kolonial. Di dalam museum ini juga terdapat beberapa ruangan yang memiliki fungsi-fungsi tertentu, seperti terdapatnya lobi pada lantai 1 dan 2, ruang pameran sayap barat dan sayap timur pada lantai 1, ruang pameran sisi timur dan ruang pengelola sisi barat pada lantai 2 , serta terdapatnya toilet pada lantai 1.

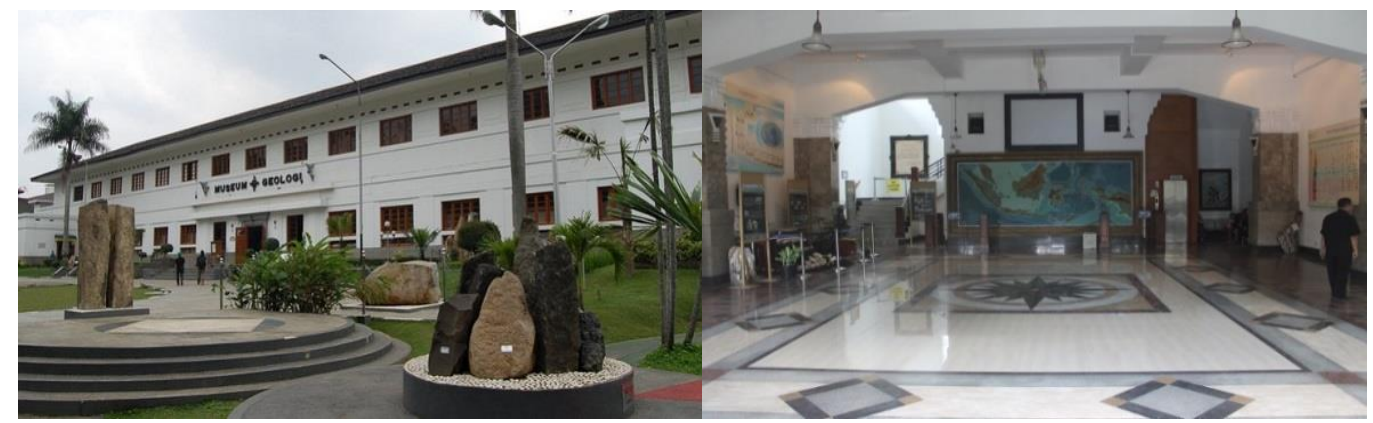

Gambar 1. Museum Geologi Bandung

b. Lingkungan

Sumber : Jejakpiknik.com, 2019

Museum ini memiliki taman yang luas di depan maupun dibelakang bangunan. Selain kegunaan nya untuk estetika atau keindahan, taman di museum ini juga sangat diminati oleh pengunjung. Bukan karena banyak tanaman atau pohon, tapi disini juga sebagai tempat penghilang penat atau capai ketika pengunjung sudah berkeliling museum. Taman berfungsi sebagai sarana pelestarian ekosistem, seperti penunjang penting bagi angin yang segar dan bersih untuk pengunjung dan bangunan. Selain itu, taman juga dijadikan tempat yang bermanfaat seperti sarana komunikasi sosial, tempat berkumpulnya komunitas, dan lain-lain.

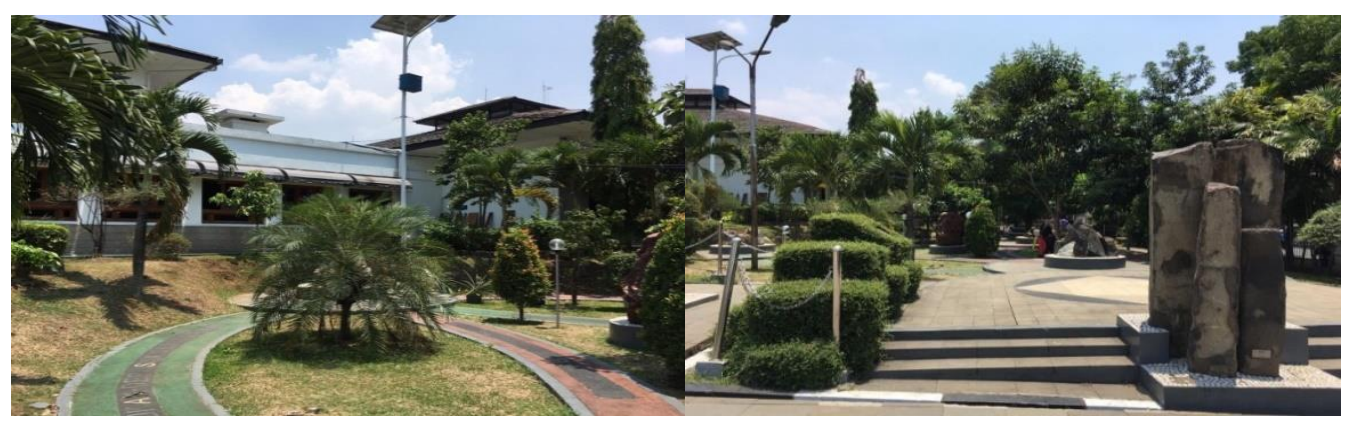

Gambar 2. Lingkungan Sekitar Museum Geologi Bandung Sumber : Data Peneliti, 2019 


\subsubsection{Data Non Fisik}

a. Pengunjung

Mayoritas pengunjung di Museum Geologi Bandung merupakan rombongan pelajar, terutama dari kalangan TK hingga tingkat sekolah tinggi. Menurut data pengelola Museum, setiap hari selalu kedatangan sekitar 1.000 pengunjung, kecuali pada Hari Sabtu serta Minggu akan meningkat sampai 2.000 pengunjung.

b. Sosial

Museum Geologi Bandung setiap tahun selalu mengadakan kegiatan sosialisasi, seperti di universitas dan tempat pendidikan lainnya. Kegiatannya yaitu seperti pameran dan seminar umum.

c. Lingkungan

Museum Geologi Bandung memiliki lingkungan sekitar yang bersih dan terjaga, jarang ditemukannya sampah, dan selalu ada tempat sampah dimana-mana. Serta, masih banyak ditemukannya pohon-pohon disekeliling museum, dan juga taman museum sebagai penunjang keasrian. Walaupun disekeliling museum terdapat jalan raya, namun polusi kendaraan tidak sampai masuk ke dalam bangunan, hal ini dikarenakan jarak museum dengan jalan yang lumayan cukup jauh serta banyaknya pohon-pohon sebagai penunjang museum untuk meminimalisir polusi yang masuk.

d. Peran masyarakat setempat

Masyarakat disekitar museum lebih banyak berprofesi sebagai pedagang, seperti menjual makanan khas Bandung dan souvenir.

\subsection{Analisis 6 Prinsip Arsitektur Hijau pada Museum Geologi Bandung}

\section{Conserving Energy / Hemat Energi}

a. Listrik

Museum ini menerapkan penghematan listrik yang baik, terutama di area lobi pada siang hari, yang mana listrik-listrik dimatikan, karena museum ini memiliki jendela pasif yang besar yang bisa memasukan cahaya alami dengan maksimal kedalam bangunan. Namun ada beberapa ruangan yang sangat minim pemakaian jendela pasif ataupun aktif, hal ini dikarenakan untuk menjaga koleksi-koleksi museum agar tetap baik dan tidak rusak, karena lamanya waktu paparan sinar matahari akan berdampak negatif, terutama pada koleksi batu yang memiliki sifat sensitif terhadap cahaya matahari.

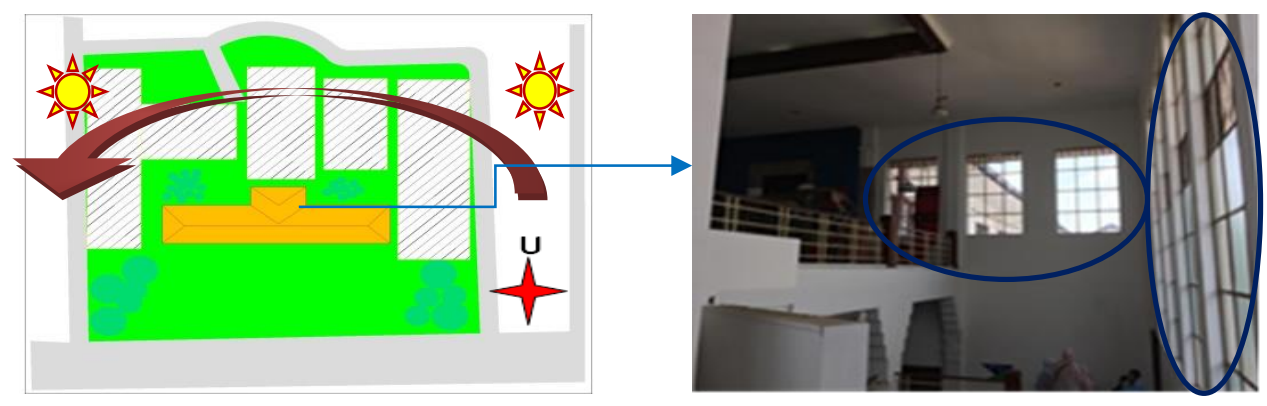

Gambar 3. Jendela untuk Memasukan Cahaya Alami Sumber : Data Peneliti, 2019

b. AC (Air conditioner )

Museum ini juga meminimalkan alat pendingin buatan / $A C$, karena terdapat bukaan jendela yang banyak baik di lantai 1 maupun 2, sehingga penghawaan didalam museum tidak terasa panas dan masih bisa dinikmati oleh pengunjung.

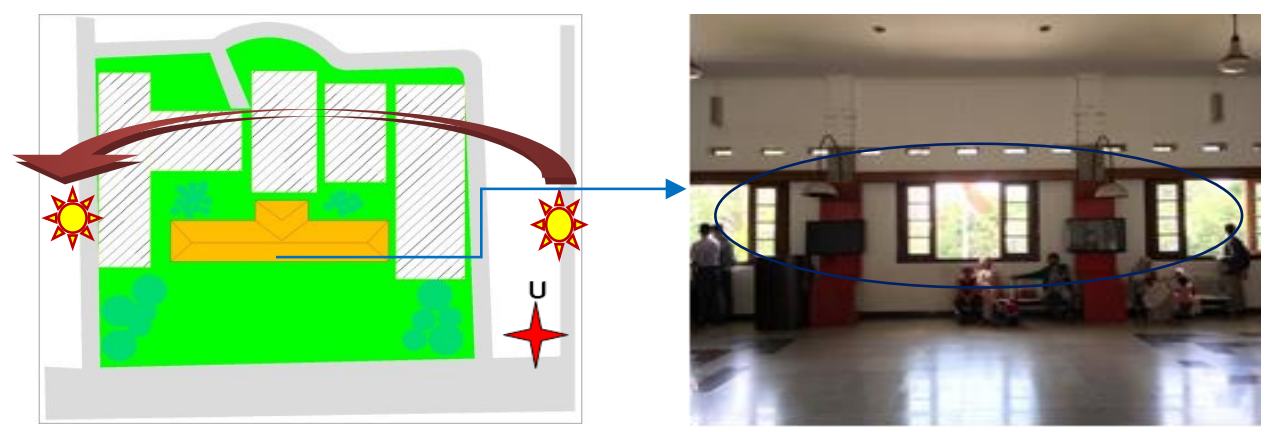

Gambar 4. Jendela untuk Memasukan Penghawaan Alami (

Sumber : Data Peneliti, 2019 
c. Orientasi bangunan

Museum Geologi Bandung memiliki sisi bangunan yang memanjang dengan menghadap utara dan selatan, sehingga dapat mengurangi radiasi matahari yang dapat menyebabkan kepanasan dan tidak nyaman yang berlebihan. Museum ini juga tidak ditemukannya bukaan pada sisi timur dan barat yang menyebabkan ruangan pada berada di sisi ini tidak mengalami kepanasan, sehingga museum ini dapat memanfaatkan dan mengatur energi cahaya matahari dengan baik.

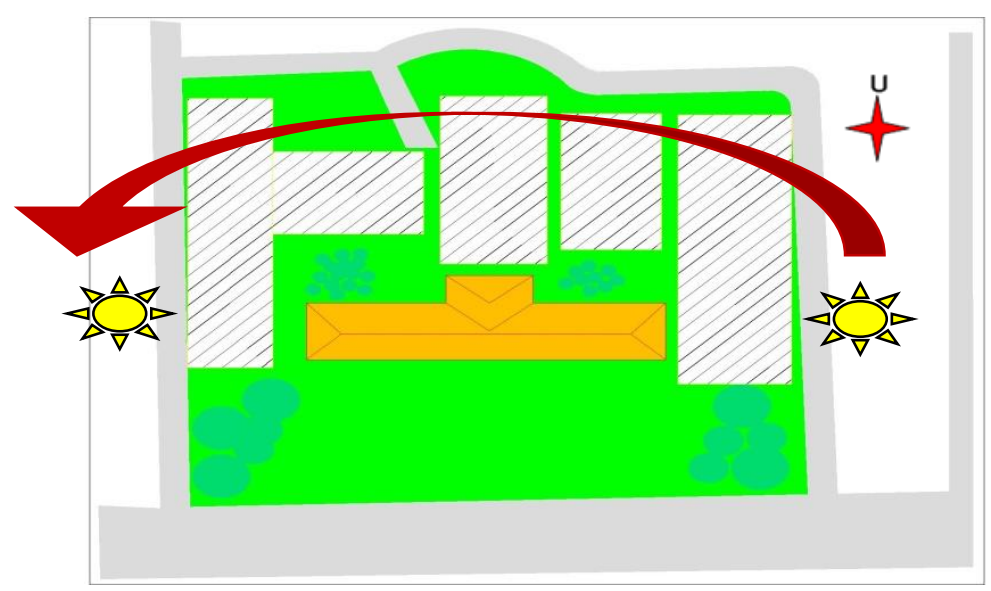

Gambar 5. Orientasi Museum Geologi Bandung

Sumber : Data Peneliti, 2019

2. Working with Climate / Menyesuaikan dengan Iklim

a. Suhu dan kelembaban

Dikarenakan Bandung memiliki iklim pegunungan yang lembab dan sejuk dan menghasilkan suhu sekitar $23.5^{\circ} \mathrm{C}$, maka dinding museum ini menggunakan ketebalan dinding sekitar $40 \mathrm{~cm}$, yang berfungsi untuk meminimalkan udara dingin yang masuk ke museum, sehingga penghawaan didalam museum masih terasa normal, yaitu tidak panas maupun dingin. Namun terkadang jika cuaca sedang panas, maka museum ini akan memanfaatkan jendela aktif untuk dibuka sebagai sirkulasi masuk dan keluarnya udara alami, sehingga pengunjung masih merasakan penghawaan yang baik.

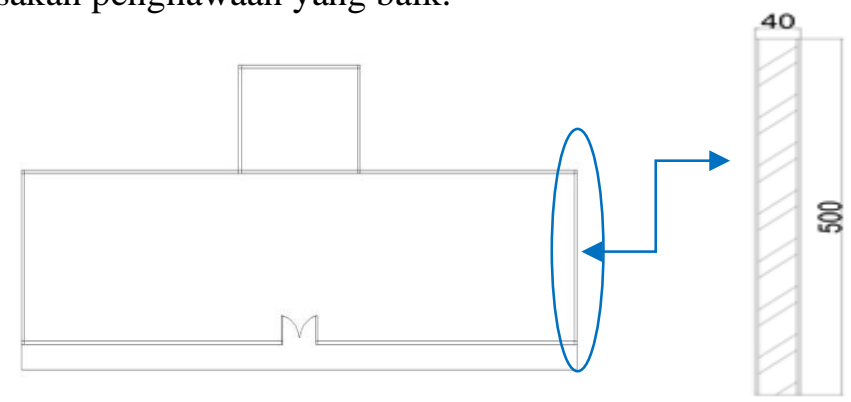

Gambar 6. Tebal Dinding Museum Geologi Bandung Sumber : Data Peneliti, 2019

\section{b. Curah hujan}

Mengingat curah hujan di Bandung memiliki rata-rata sekitar $200.4 \mathrm{~mm}$ dengan jumlah hari hujan ratarata 21.3 hari perbulan, maka atap pada museum ini memiliki kemiringan yang cukup curam sekitar $45^{\circ}$, yang membuat air hujan langsung turun ke bawah dan tidak tergenang atau terhambat di atas.

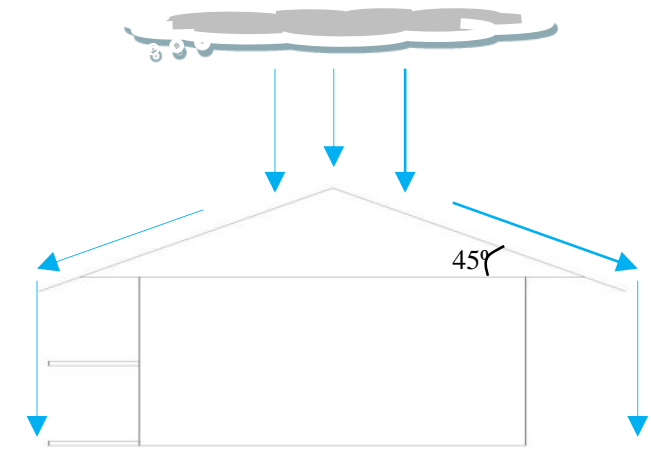

Gambar 7. Kemiringan Atap Museum Geologi Bandung Sumber : Data Peneliti, 2019 
3. Respect for Site / Menanggapi terhadap Tapak Bangunan

Museum ini memiliki lahan di depan serta di belakang, sebagian besar berfungsi sebagai ruang terbuka hijau. Bangunan Museum ini mendapatkan sekitar 44\% dari luas lahan $\pm 8.342,52 \mathrm{~m}^{2}$, sehingga museum ini masih memikirkan tapak sekitar 56\% sebagai tempat kegiatan aktif maupun pasif, seperti taman, area tumbuhan, dan lain-lain. Keberadaan museum ini juga tidak merusak lingkungan sekitar, baik dilihat dari segi konstruksinya maupun bentuk serta pemilihan materialnya.

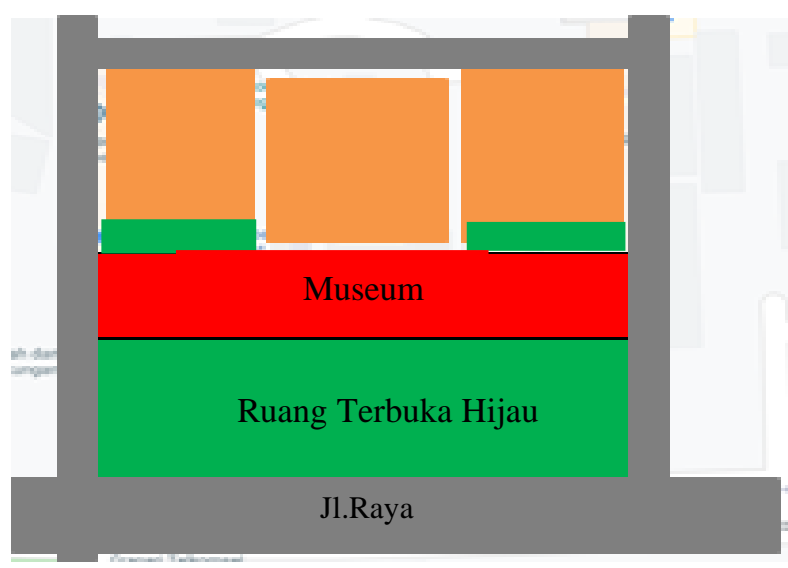

Gambar 8. Site Museum Geologi Bandung Sumber : Data Peneliti, 2019

4. Respect for User / Menanggapi terhadap Pengguna Bangunan

a. Universal

Museum ini kurang memperhatikan dalam akses pengguna yang berkebutuhan khusus, terutama jika ingin naik ke lantai 2, tidak ada lift melainkan tangga. Namun disisi lain, terdapat toilet khusus difabel dengan ukuran yang mencukupi untuk masuknya kursi roda dan bergerak bebas di dalamnya, yaitu dengan luas $3 \times 3$ $\mathrm{m}$. Bukan hanya itu, pintu toilet khusus difabel juga memiliki lebar $1 \mathrm{~m}$, sehingga pengguna difabel bisa dengan mudah untuk masuk. Serta untuk ketinggian duduk kloset memiliki ketinggian $50 \mathrm{~cm}$, maksudnya bagian bawah kloset menempel dengan lantai, hal ini bertujuan memudahkan pengguna difabel untuk turun dari kursi roda ataupun sebaliknya dari kloset ke kursi roda.

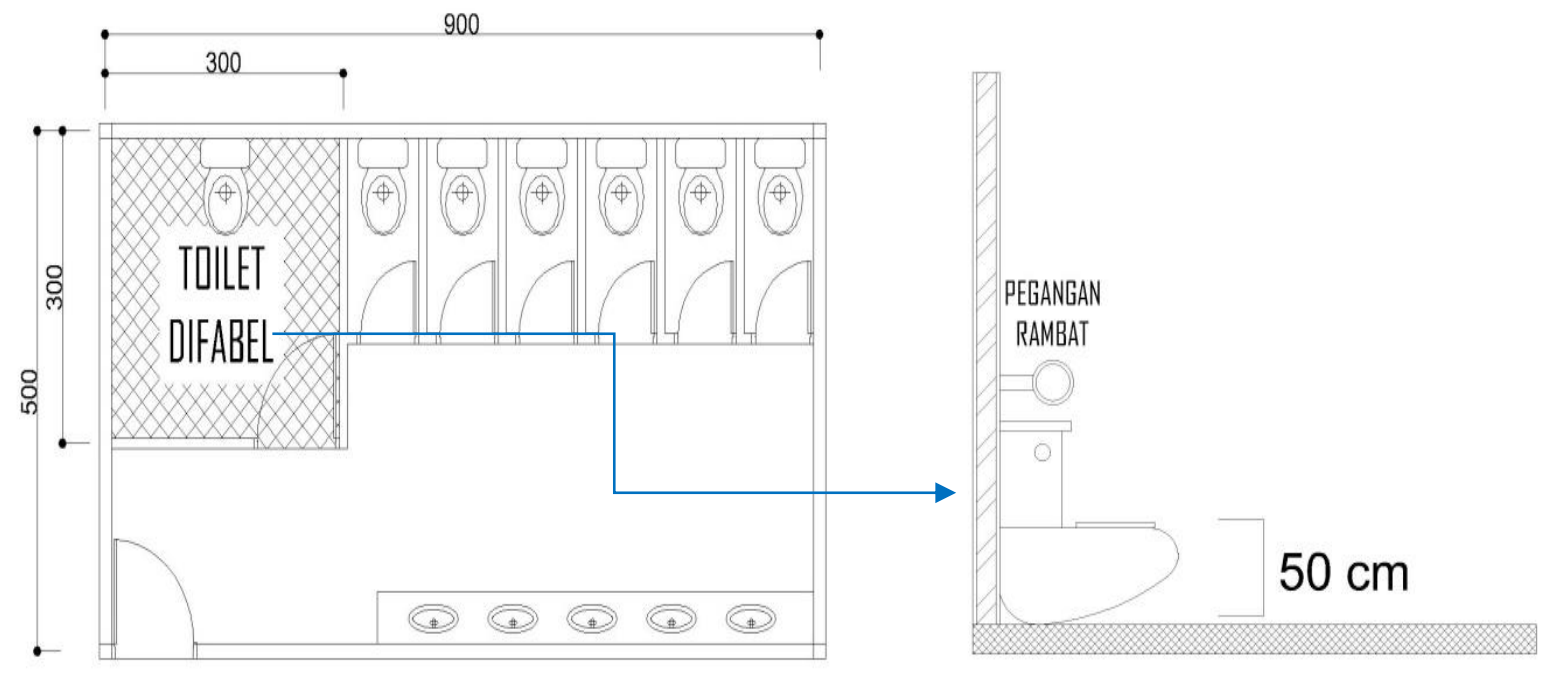

Gambar 9. Toilet Difabel Museum Geologi Bandung Sumber : Data Peneliti, 2019

b. Material dinding

Selain adanya pencahayaan alami dan penghawaan alami, tentu pengunjung maupun pengelola museum akan tetap merasakan kenyamanan. Karena museum ini terdapat lantai yang berbahan marmer serta dindingnya yang tebal membuat keadaan didalam museum tetap sejuk walaupun jika diluar museum sedang panas, ataupun sebaliknya didalam museum tidak akan dingin walaupun di luar sedang keadaan hujan. 


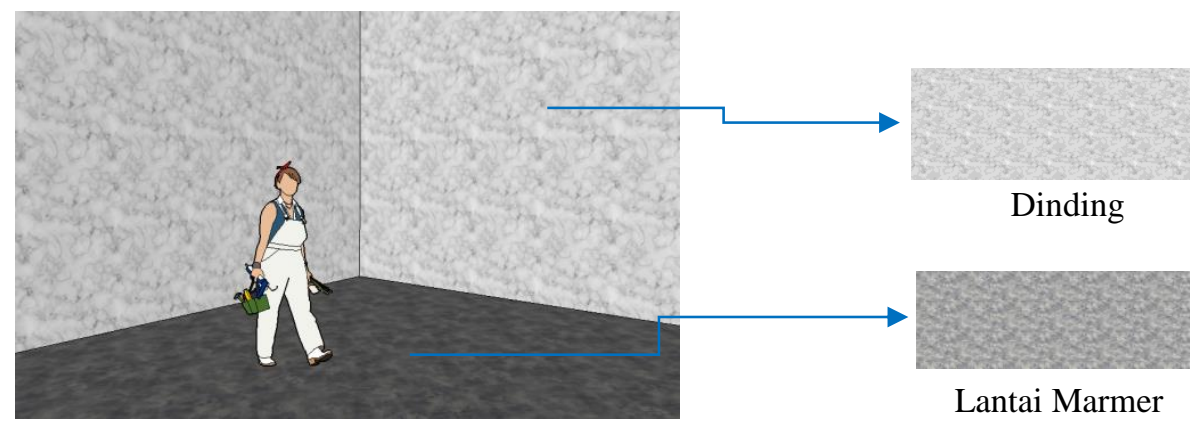

Gambar 10. Material Dinding dan Lantai Museum Geologi Bandung Sumber : Data Peneliti, 2019

\section{Limitting New Resources / Meminimalkan Sumber Daya}

Museum ini dibangun memaksimalkan bahan yang biasa digunakan pada umumnya. Seperti batu batako untuk dinding yang tidak memerlukan bahan perekat yang tebal, sehingga bisa jadi lebih hemat, lebih ringan dan memiliki daya ketahanan yang cukup kuat. Jendela dan pintu yang terbuat dari kayu yang memiliki sifat solid alias padat. Serta atap yang terbuat dari metal dengan kelebihan daya tahan yang cukup tinggi dan baik, bobot yang ringan, harga yang murah, ramah lingkungan, pemasangan mudah dan cepat sehingga bisa menghemat waktu, serta cocok untuk rawan gempa.

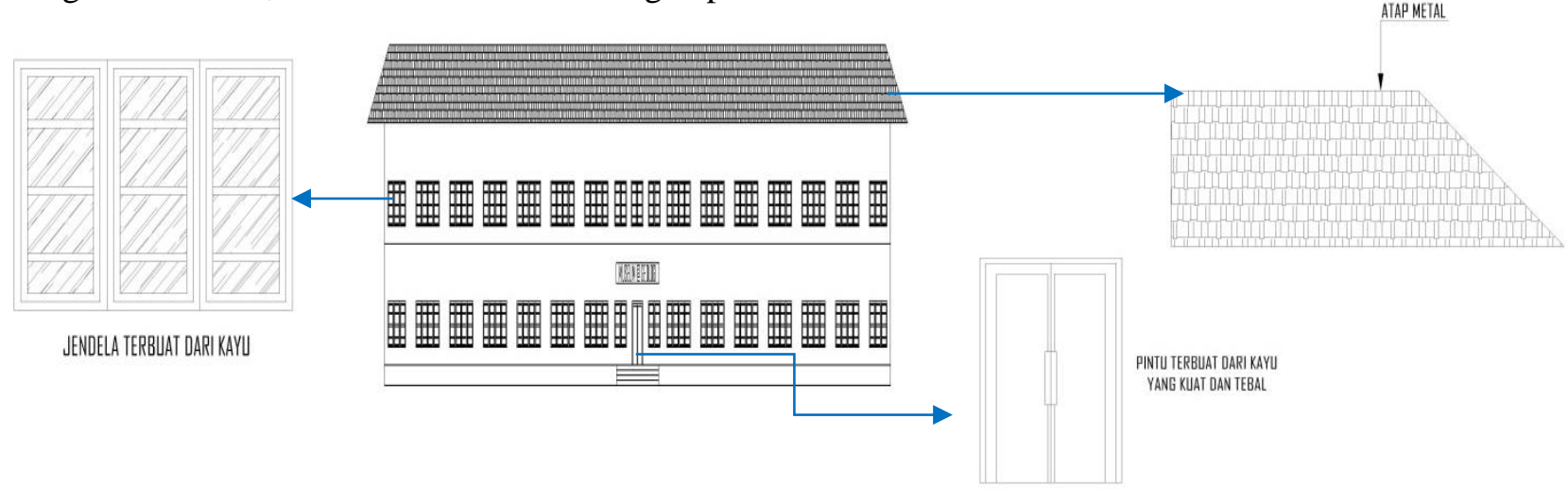

Gambar 11. Material pada Museum Geologi Bandung Sumber : Data Peneliti, 2019

6. Holistic Menyeluruh

Secara keseluruhan, Museum Geologi Bandung lebih banyak atau maksimal dalam menerapkan prinsip arsitektur hijau, baik dari segi penghematan energinya, mampu menyesuaikan dengan iklim sekitar, tidak mengganggu lahan dan ekosistem sekitar, mampu memperhatikan pengunjung museum, serta menggunakan bahan yang ramah lingkungan.

\section{Kesimpulan}

Arsitektur hijau bukan hanya memperhatikan antara bangunan dengan lingkungan sekitar saja, namun juga harus memperhatikan beberapa prinsip, seperti penghematan energi yang baik, mampu beradaptasi dengan iklim sekitar, menanggapi keadaan lahan dan ekosistem sekitar, menanggapi pengguna atau pengunjung bangunan, meminimalkan sumber daya, serta kesatuan dari prinsip pertama hingga prinsip terakhir.

Penghematan pada museum geologi merupakan suatu hal yang penting karena harus memperhatikan sumber energi, terutama listrik dan AC yang menjadi sumber penggunaan yang sering kita pakai sehari-hari. Suatu bangunan juga harus dirancang dengan memperhatikan iklim setempat, karena iklim sangat berpengaruh terhadap bentuk bangunan serta pemilihan materialnya.

Bentuk museum dan pemilihan material juga harus merespon terhadap beberapa dampak iklim setempat, seperti kemiringan atap yang curam merupakan bentuk respon dari bentuk bangunan terhadap dampak iklim, yaitu curah hujan yang tinggi. Pada kawasan ataupun lahan dimana bangunan museum berada, harus memastikan bahwa eksisting di sekitarnya tetap terjaga, tidak merusak lingkungan, dan konstruksinya tidak mengganggu lahan. Hal ini untuk menunjang keseimbangan antara bangunan museum dengan lingkungan sekitar, terutama pohon-pohon yang menjadi sumber penghijauan. 
Selain itu, aspek universal dan kenyamanan bagi pengunjung adalah prinsip penting bagi penerapan suatu bangunan, terutama museum. Karena harus memperhatikan segala kebutuhan bagi pengunjung yang berkebutuhan khusus maupun pengunjung yang normal, dengan ini memudahkan pengunjung untuk berjalan dan merasakan kenyamanan baik didalam bangunan maupun sekitarnya. Untuk material yang digunakan juga harus memiliki nilai yang ekonomis, mudah didapatkan, memiliki daya tahan yang kuat dan lama, ramah lingkungan, dan pemasangan yang cepat sehingga bisa menghemat waktu dan biaya. Selain itu, merancang sebuah tempat yang bisa mendaur ulang seperti penampungan air juga merupakan hal yang penting, karena dengan ini dapat memanfaatkan sumber daya dan menghemat pengeluaran.

\section{Referensi}

Afifah, R., Anisa, \& Hakim, L. (2018). PENERAPAN KONSEP ARSITEKTUR HIJAU PADA BANGUNAN PUSAT PENELITIAN DAN PENGEMBANGAN TANAMAN HERBAL DI LEMBANG BANDUNG. Jurnal Arsitektur PURWARUPA Volume 2 No 2 September 2018 : 93-98, 94.

Henriyanto, A. (2016). PERENCANAAN PUSAT TEKNOLOGI INFORMASI DI KENDARI DENGAN PENDEKATAN ARSITEKTUR HIJAU. Volume 1 No 2| Agustus 2016, 84.

Kakunsi, I. E. (2013). ANALISIS PELAPORAN DAN KONTRIBUSI PAJAK BUMI DAN BANGUNAN PADA DINAS PPKAD KABUPATEN KEPULAUAN SANGIHE. Jurnal EMBA Vol.1 No.4 Desember 2013, Hal. 1934-1945, 1934-1945.

Kalukar, S. J., Tumaliang, H., \& Tuege, M. (2015). Desain Instalasi Penerangan Pada Bangunan Multi Fungsi. $12-13$.

Karyono, T. H. (2010). Green Architecture Pengantar Pemahaman Arsitektur Hijau di Indonesia. Jakarta: PT RAJAGRAFINDO PERSADA.

Priatman, J. (2002). "ENERGY-EFFICIENT ARCHITECTURE" PARADIGMA DAN MANIFESTASI ARSITEKTUR HIJAU. DIMENSI TEKNIK ARSITEKTUR Vol. 30, No. 2, Desember 2002: 167 - 175, 167-175.

Rusadi, P., Purwatiasning, A. W., \& Satwikasari, A. F. (2019). PENERAPAN KONSEP ARSITEKTUR HIJAU PADA PERENCANAAN AGROWISATA KOPI DI TEMANGGUNG. Jurnal Arsitektur PURWARUPA Volume 03 No 4 September 2019, 25.

Dewanto, R. (2010, januari 11). bangunan publik. Retrieved from urban issues: http://www.rudydewanto.com/2010/01/bangunan-publik.html

Wulandari, A. A. (2014). DASAR-DASAR PERENCANAAN INTERIOR MUSEUM. HUMANIORA Vol.5 No.1 April 2014: 246-257, 246-257.

Susanto, H. (2014). MUSEUM BERBASIS ANDROID PADA MUSEUM RANGGAWARSITA SEMARANG DENGAN KOMPETENSI PROTOTYPE. 1.

Noor, A., \& Karwina, W. (2012). Persepsi Wisatawan Domestik Terhadap Kualitas Pelayanan Museum Geologi Bandung . Industrial Research Workshop and National Seminar 2012 , 377-384.

Putri, A. F., Singgih, E. P., \& Gunawan. (2019). KONSERVASI ENERGI DAN AIR PADA FASILITAS OLAHRAGA INDOOR DENGAN PENDEKATAN ARSITEKTUR HIJAU DI KOTA DEPOK JAWA BARAT . SENTHONG, Vol.2, No.1, Januari 2019, 77-88.

Rachmayanti, S., \& Roesli, C. (2014). GREEN DESIGN DALAM DESAIN INTERIOR DAN ARSITEKTUR . HUMANIORA Vol.5 No.2 Oktober 2014: 930-939, 930-939 .

Syarif, E., \& Amri, N. (2017). Arsitektur Hijau pada Morfologi Permukiman Tepi Sungai Tallo. Jurnal Lingkungan Binaan Indonesia 6 (2), 82-87, 82-87.

Utsman, M. R., Suroto, W., \& Winarto, Y. (2019). PENERAPAN PRINSIP ARSITEKTUR HIJAU PADA BANGUNAN KANTOR SEWA DI SURAKARTA. SENTHONG, Vol. 2, No.2, Juli 2019, 415-424. 